\title{
Root Hairs Matter at Field Scale for Maize Shoot Growth and Nutrient Uptake, But Root Trait Plasticity is Primarily Triggered by Texture and Drought
}

Doris Vetterlein ( $\boldsymbol{Q}$ doris.vetterlein@ufz.de)

UFZ Environmental Research Centre https://orcid.org/0000-0003-2020-3262

Maxime Phalempin

UFZ Environmental Research Centre

Eva Lippold

UFZ Environmental Research Centre

Steffen Schlüter

UFZ Environmental Research Centre

\section{Susanne Schreiter}

UFZ Environmental Research Centre

Mutez Ahmed

University of Bayreuth

Andrea Carminati

Institute of Terrestrial Ecosystems

Patrick Duddek

Institute of Terrestrial Ecosystems

Helena Jorda

Forschungszentrum Juelich $\mathrm{GmbH}$

Patrick Bienert

Technical University of Munich

Desiree Bienert

Technical University of Munich

Mika Tarkka

Helmholtz Centre for Environmental Research - UFZ

Minh Ganther

Helmholtz Centre for Environmental Research - UFZ

Eva Oburger

University of Natural Resources and Life Sciences

Michael Santangeli

University of Natural Resources and Life Sciences

Mathieu Javaux 
Forschungszentrum Juelich $\mathrm{GmbH}$

\section{Jan Vanderborgth}

Forschungszentrum Juelich $\mathrm{GmbH}$

\section{Research Article}

Keywords: mechanical impedance, nutrient availability, rhizosphere, root diameter, root length density, root to shoot ratio, water availability, Zea mays

Posted Date: February 1st, 2022

DOI: https://doi.org/10.21203/rs.3.rs-1277067/v1

License: (9) This work is licensed under a Creative Commons Attribution 4.0 International License. Read Full License 


\section{Abstract}

Aims: Root hairs are important for uptake, especially for nutrients with low mobility in soils with high sorption capacity. Yet, this has rarely been demonstrated in the field during a whole growing season. Mutants with defective root hairs are expected to have lower nutrient uptake, unless they compensate with more root growth. Since root hairs can also contribute to the plant's water uptake their importance could change over the course of a growing season.

Methods: The root hair mutant rth3 of Zea mays and the corresponding wild-type were grown for two years under field conditions on sand and loam.

Results: Shoot growth and P and K uptake of the plants were promoted by the presence of hairs at all growth stages. Differences between genotypes were greater on loam than on sand until tassel emergence, because additional exploitation by hairs is more relevant in loam. Compensation for the absence of root hairs by increased root growth was not observed in absolute terms. The root to shoot ratio was higher for rth 3 than for wild-type. Root traits showed high plasticity in response to texture, the most salient being a greater mean root diameter in sand, irrespective of genotype. The mechanism causing the increase in mean root diameter is still unknown. Root length density was higher in sand, which can be explained by a greater need for exploration than exploitation in this substrate.

Conclusion: The greater investment in root growth on sand compared to loam is expected to alter the long-term carbon balance.

\section{Introduction}

\section{Root hairs}

It has been demonstrated numerous times in controlled condition experiments that root hairs are important for nutrient uptake, in particular for those with low mobility like phosphorus $(P)$ and potassium (K) ((Bates and Lynch 2001; Bienert et al. 2021; Jungk 2001). A favourable role of hairs for water uptake, in particular under conditions of limited water availability, has also been suggested, but with contradicting results (Cai et al. 2021; Carminati et al. 2017a; Kwasniewski et al. 2016; Marin et al. 2020; Segal et al. 2008). Hairs increase the surface area for uptake and hence the soil volume influenced by an individual root at relatively low carbon costs (Gahoonia and Nielsen 1997; Lynch and Ho 2005). They have been shown to increase the size of the depletion zone for immobile nutrients, to facilitate diffusion of exudates like organic acids or exoenzymes, and, as a result, to alter microbiome composition ((Gebauer et al. 2021; Marin et al. 2020) and citations therein). It is therefore expected that root hairs improve crop tolerance to abiotic stress such as low water and nutrient availability. As pointed out by Marin et al. (2020) most studies investigating the functions of root hairs have been conducted under controlled conditions, i.e. in sieved, homogenized soils, under artificial lighting, with limited soil volume, and for young growth stages only. Very few studies have attempted to validate these laboratory findings under field conditions (Gahoonia and Nielsen 2004; George et al. 2014; Marin et al. 2020; Nestler et al. 
2016; Nestler and Wissuwa 2016; Ruiz et al. 2020). Among those, only the one referred to by Marin et al. (2020) and Ruiz et al. (2020) covered a range of plant parameters throughout the whole growing season including data on climatic conditions and soil water availability. In their trial root hairs did not confer a notable advantage to barley under optimal (nutrients and water) conditions. Yet, under soil water deficit root hairs improved plant water status and stress tolerance, while promoting shoot $\mathrm{P}$ accumulation. There is still a pressing need to conduct further field studies addressing the function of root hairs while continuously monitoring plant growth as well as water and nutrient status of plants and soils, including the effect of soil texture on such relations. However, such experiments need to take the interplay of different root traits into account, including possible compensation measures. They also have to disentangle in more detail which traits contribute to soil exploration and which ones will rather improve soil exploitation. Such studies are now possible, utilizing root hair mutants.

\section{Plasticity of root traits}

High plasticity in response to environmental conditions is a key property of roots and crucial for resource acquisition (Hodge 2004; Morris et al. 2017). The open questions include how a large number of traits are integrated upon environmental perturbation (Miguel et al. 2015; Wen et al. 2019; York et al. 2016), and when a particular trait is missing - which traits will be modified to substitute for the hair function. Some authors reported compensation by larger investment into root growth in general (Dodd and Diatloff 2016; Klamer et al. 2019) or fine roots in particular (Klamer et al. 2019). In a laboratory experiment comparing two maize genotypes (wild-type to the corresponding root hair mutant rth3) in two soil textures, a shift in root to shoot ratio could be confirmed but no plastic adaptation of root system architecture to the lack of root hairs (Lippold et al. 2021). However, both genotypes showed large plasticity of root architecture and in particular root diameter in response to texture. Whether these findings would hold under field conditions with unrestricted soil volume and fluctuating water supply is an open question.

\section{Exploration and exploitation - the integration of root traits}

Some root traits alter soil exploration, i.e. the size of the soil domain explored by roots, by modulating root architecture (i.e. axial root growth angle, growth rate, number of axial roots, later root branching) (Fitter 1987; Lynch 2013; York et al. 2013). At field scale, this can be measured as differences in the distribution of root length density over depth and its change over time. Another trait primarily related to exploration is the degree of mycorrhizal colonisation, supposed to reflect the abundance of extra-radical mycelium. Soil exploration can be distinguished from soil exploitation, i.e. how thoroughly resources are acquired within a given soil domain without further soil exploration (Fitter 1987). Root hairs improve soil exploitation similarly to other rhizosphere modifications, like the release of exudates, increased activity or number of mineral nutrient transporters, and enhanced root-soil contact (root diameter, mucilage, rhizosphere porosity) (York et al. 2013). The root length density within a given volume has an impact on exploitation as well. Exploitation strategies make a difference in environments with patchy, heterogeneous distribution of resources or a large proportion of nutrients with low mobility (Hodge 2006). In turn, exploration is expected to be more successful if resources are only available in low amounts throughout the soil profile or if resources are only available at larger depths (distance to the seed). Hence, 
environmental conditions like resource availability and distribution are expected to shape the plastic response to the lack of root hairs and the genotype specific integration of different root traits. For the latter, metabolic costs for different traits might be additional driving factors (Lynch et al. 2021). Experiments and in silico studies have shown that maintenance respiration comprises a significant part of plant carbon (C) budget; it can be lowered by aerenchyma formation, and it is also affected by root diameter and root hair formation (Jaramillo et al. 2013; Lynch and Ho 2005; Postma and Lynch 2011). At the field scale, apart from morphological and anatomical root traits, root to shoot ratio is a good indicator for plant C budget (Ordóñez et al. 2020).

Here, we present the results of a field experiment comparing a maize wild-type (WT) to a corresponding root hair mutant (rth3) grown in two soil textures (loam, sand) to introduce variability in nutrient mobility. With this we expand a previous twin laboratory based experiment (Lippold et al. 2021) with the same treatments to the field scale following the challenge of upscaling laboratory based results (Vetterlein et al. 2021). As in the twin laboratory experiment nutrient supply was low, but the whole growing season under rain fed water supply was investigated instead of three weeks under optimal water supply. We investigated the following hypothesis:

H1: Hairs matter at field scale for biomass production and nutrient uptake, in particular for loam as mobility of nutrients is low.

$\mathrm{H} 2$ : Root hairs might contribute to plant water acquisition, in particular under drought stress. This should result in a later onset of drought stress under water limiting conditions. As the mechanisms discussed are supposed to decrease water potential gradients in the rhizosphere, the effect is expected to be more relevant in sand compared to loam.

H3: Root hair mutant will show plasticity in other root traits to compensate for the lower surface area. This is reflected in greater root to shoot ratio, increase in root length densities, larger share of fine roots, more intense mycorrhizal colonization, alteration of exudation and related root gene expression. All of these will impact rhizodeposition and, as a consequence, microbial composition and activity.

H4: As initial differences in nutrient availability between textures are levelled by fertilisation, no specific texture related differences in root traits are expected.

Note that for some specific aspects related to the above listed hypotheses there are individual publications referring to the same field experiment and providing an in-depth discussion of the methods used and the results obtained. Here we will only refer to the results when appropriate. We refer to Jorda et al. for plant water relations, Ganther et al. for root gene expression, Santangeli et al. for root exudation and Rosskopf et al. for soil mechanical properties - all available in the same special issue.

\section{Materials And Methods Experimental design}


The soil plot experiment was carried out in 2019 and 2020 at the Bad Lauchstädt research station in Germany $\left(51^{\circ} 23^{\prime} 36.10^{\prime \prime} \mathrm{N} ; 11^{\circ} 52^{\prime} 30.29 \mathrm{E}\right)$. Experimental design, maize genotypes, substrates, fertilization, agronomic measures and growth stages selected for sampling as well as monitoring devices for plant water relations are all described in detail in Vetterlein et al. (2021) along with the motivation of conducting twin experiments at laboratory and field scale in order to extrapolate results. Therefore, these topics are only briefly described here.

The basic design is a two factorial, randomised block design with six replications. Factor one is substrate (texture) with two levels (loam (L), sand (S)). Factor two is the Zea mays genotype with two levels comprising wild-type (WT), and a root hair mutant (rth3).

The monogenic mutant $r$ th 3 is transposon induced and shows normal root hair initiation but disturbed elongation. The mutant shows no apparent aberrant shoot phenotype, but yield is reduced by 20 to $40 \%$ compared to the wildtype (Hochholdinger et al. 2008). The mutated gene encodes a GPI-anchored COBRA-like cell wall protein RTH3 that is involved in the organization of the synthesized cellulose (Hochholdinger et al. 2018). The rth3 mutants used in these experiments are genetically highly homozygous because they have been backcrossed to the inbred line B73 for more than eight generations.

The substrate loam was obtained by excavating $700 \mathrm{t}$ of a haplic Phaeozem soil (from 0 to $50 \mathrm{~cm}$ depth) in Schladebach, Germany ( $\left.51^{\circ} 18^{\prime} 31.41^{\prime \prime} \mathrm{N} ; 12^{\circ} 6^{\prime} 16.31^{\prime \prime} \mathrm{E}\right)$. The substrate sand was obtained by repeated mixing and sieving of loam with quartz sand ( $550 \mathrm{t}$, WF 33, Quarzwerke Weferlingen, Germany). Setting up the field plots started right after the sieving operation in October 2018 . Individual field plots $(11 \times 3.1$ $\mathrm{m}$ ) were excavated to a depth of $1 \mathrm{~m}$. Vertical side walls were covered with a root barrier. The bottom of the plots was filled with a $25 \mathrm{~cm}$ gravel layer (0/32) and a drainage textile was then placed on top of the gravel. Substrates were then filled up to the original soil surface with a thickness of $75 \mathrm{~cm}$. The loam was gradually placed in layers of $15 \mathrm{~cm}$ by a wheel loader, evened out with wheel loader bucket and compacted with a vibrating plate. This procedure proved to be suitable in a pilot experiment, as X-ray CT scans of extracted undisturbed soil cylinders showed no layering (Fig. 3 in (Vetterlein et al. 2021)). For treatment (S), sand was packed similarly; however, no vibrating plate was used.

The aim of fertilisation was to achieve a nutrient level in the range between slightly nutrient deficient to adequate nutrition for the wild-type genotype, in order for any investment into resource acquisition to payoff. Initial differences in nutrient availability between substrates (Tab. S1) should ideally be compensated by fertilisation. As a result of pre-trials N, P, K, and Mg were added at a dose twice as high in sand compared to loam, and $\mathrm{Ca}$ as well as micronutrients were only applied to sand (Tab. S2). Fertilisers were surface applied, $50 \%$ prior to seeding, and the remaining 50\% after first sampling. Fertilisation was the same in 2019 and 2020. Maize was sown to a depth of $5 \mathrm{~cm}$. Distance within row was $20 \mathrm{~cm}$; between rows $45 \mathrm{~cm}$. This resulted in six rows with 54 plants each and a planting density of 9.5 plants $\mathrm{m}^{-2}$; corresponding to a soil volume per plant of $78.935 \mathrm{dm}^{3}$ down to a depth of $75 \mathrm{~cm}$. No pesticides were applied and weeding was done by hand. No heavy machinery was allowed to pass over the plots to avoid modification of soil structure. Temperature and precipitation for the research station Bad Lauchstädt for 
2019 and 2020 are provided in Fig. S1. Note that irrigation was required to allow germination in 2019 and to avoid damaging crop losses in 2019 and 2020.

For shoot and root sampling events specific growth stages according to $\mathrm{BBCH}$-scale were selected (Bleiholder et al. 2001). The BBCH 14 growth stage (four leaves unfolded) was selected as the first sampling point as this corresponds to the developmental stage achieved after 21 days in the twin laboratory experiment (Lippold et al. 2021) - in 2019 BBCH 14 was reached 42 days after planting (DAP). The BBCH 19 growth stage (nine or more leaves unfolded) was selected as second time point representing exponential growth (DAP 63 in 2019). The BBCH59 growth stage (end of tassel emergence) was selected as time point during the transition from vegetative to generative growth (DAP 98 in 2019) and the $\mathrm{BBCH} 83$ growth stage (early dough) as a growth stage representing ripening phase (DAP154 in 2019).

Soil water status was monitored throughout 2019 and 2020 with soil matric potential and soil water content sensors installed in four depths $(10,20,40$ and $60 \mathrm{~cm})$ in one representative plot per treatments (Vetterlein et al. 2021) (Jorda et al. in preparation).

\section{Shoot biomass sampling}

At $\mathrm{BBCH} 14,19$ and 59 three representative plants per plot were sampled. The youngest unfolded leaves were separated and tissue was dried at $65^{\circ} \mathrm{C}$ until constant weight. Youngest unfolded leaves and the remainder of the shoot were analysed separately. Nutrient concentrations in youngest unfolded leaves were used to derive plant nutrient status, analyses of remainder shoot and youngest leaves were used to calculate shoot nutrient content. Nutrient uptake was defined as shoot nutrient content divided by root surface area. For nutrient analyses tissue was chopped (Retsch SM2000) and subsamples were milled (30-50 min at 28/s with a Retsch mill MM400). C and N were analysed by combustion with a CNS analyser (vario EL cube, Elementar, Germany). Approx. $50 \mathrm{mg}$ plant material was weighed and used for determining $\mathrm{P}, \mathrm{K}$ and $\mathrm{Ca}$ concentrations using an inductively coupled plasma optical emission spectrometry (ICP-OES, iCAP 6000, Thermo Fisher Scientific, Dreieich, Germany) after pressure digestion with nitric acid and hydrogen peroxide (ultraCLAVE V, MLS, Germany).

\section{Root sampling}

Three root cores per plot were taken at several depths between rows in $10 \mathrm{~cm}$ distance from the sampled plant foot. The motorized root corer (Humax Bohrsonden, Martin Burch AG, Switzerland) was equipped with a $20 \mathrm{~cm}$ long and $5 \mathrm{~cm}$ in diameter cartridge and samples were taken at 0-20,20-40 and 40-60 cm depth, resulting in nine samples per plot which were washed over $0.65 \mathrm{~mm}$ sieves. Hereby, the sample was cleared of small stones and litter and the obtained roots were stored in a $50 \%$ alcohol solution (i.e. diluted Rotisol $\left({ }^{\circledR}\right)$. Subsequently, roots were scanned at $720 \mathrm{dpi}$ with a $35 \mu \mathrm{m}$ resolution using a flatbed scanner (EPSON perfection V700). Root traits were analysed using the software WinRhizo 2019 (Regent Instruments, Canada). 
Sampling the remaining depth down to the drainage layer at $75 \mathrm{~cm}$ was omitted in order to avoid damage of the drainage fleece. For BBCH 14 only 0-20 cm depth was sampled. For BBCH 19 all depths were sampled in 2020, but in 2019 40-60 cm depth was not yet sampled.

In 2020 dead roots from 2019 were detected in sand treatments. Sorting out the dead roots by colour and appearance would have been too tedious and subjective. Hence, root degradation rate was estimated by a modelling approach assuming that most of the roots detected at BBCH 14 in 2020 were dead roots. In addition, it was assumed that degradation rate is temperature dependent and follows a first order kinetic. The model is described in detail in Jorda et al. in preparation. Root length densities without correction are shown in Fig. S2.

\section{Mycorrhization}

After scanning with WinRhizo, the degree of mycorrhizal colonization was determined for subsamples consisting of ten fine root $(\varnothing<1 \mathrm{~mm})$ segments. Fine roots selected were stained with ink (4001 Pelikan) after clearing roots in $\mathrm{KOH}(10 \%)$ (Vierheilig et al. 1998). For each sample, 100 fields of view were evaluated under light microscope. Following McGonigle et al. (1990), the presence of arbuscules, hyphae and vesicles was scored separately. Since the extent of hyphal colonisation correlated highly with the level of arbuscule formation ( $\mathrm{p}<0.001$ according to ANOVA), and vesicle formation was rare in maize roots ( $<8 \%$ of the roots), only the percentage of arbuscule formation is presented.

\section{Rating of root hairs}

The presence of root hairs was scored for the roots used to determine mycorrhizal colonisation, in order to confirm the presence and sum up the numbers of elongated hairs in wild-type and to assess if the rth 3 root hair elongation defect (Hochholdinger et al. 2008) was consistently expressed under field conditions.

\section{Ratio of root cortex: vascular bundle}

Root axes were randomly selected from the field samples used for WinRhizo scanning. Ten segments per plot were analysed for root diameter, for each segment ten free-hand cross sections were cut and analysed by light microscopy for root diameter and the diameter of the vascular bundle. The ratio of cortex to vascular bundle diameter was then calculated. For the cross sections evaluated the share of aerenchyma was scored. The scale used is provided with the respective figure.

\section{Root to shoot ratio}

As part of the measurement of root exudation by the soil-hydroponic hybrid method carried out in the same field experiment (Oburger et al. personal communication), the ratio of root fresh weight to dry weight and the ratio of root volume to fresh weight were determined. From these ratios a conversion factor for root volume (RV) (determined with WinRhizo) to root dry weight (RDW) was derived: RDW= $\mathrm{RV} * 0.117 \mathrm{~g} \mathrm{~cm}^{3}$. Root dry weights from different depths were multiplied by the respective volume corresponding to an individual plant (derived from planting density) to calculate the root dry weight per plant. Shoot dry weight per plant was measured directly (see shoot biomass sampling). 


\section{Water use efficiency (WUE)}

WUE was calculated using mean values of shoot (and root) dry weight divided by soil water extraction. The data on soil water extraction were taken from Jorda et al. in preparation. They are based on cumulative water extraction measured for the growing seasons 2019 and 2020 in the same field experiment. As data for cumulative soil water extraction are only available for one replicate per treatment, no statistics could be provided for WUE.

\section{Statistics}

For all figures, standard errors and mean values of six replicates (plots) are provided. Technical replicates within plots are not considered for statistics. A log-transformation was used prior to statistical analyses when normal Q-Q plots and Shapiro test indicated that the normal distribution criterion was not met. The software R version 3.53 ( $R$ Core Team 2018) and the libraries Ime4, car, multcomp, ggplot and emmeans were used. A two-factorial ANOVA for the fixed factors substrate, genotype and their interaction was conducted in conjunction with Tukey's HSD test. The fixed factor depth was additionally used for some root trait data. Significant differences $(p<0.05)$ between treatments are displayed with different letters in the figures.

\section{Results}

\section{Environmental conditions}

Both years $(2019,2020)$ were characterized by low temperatures in May (BBCH 0 - BBCH 14) and exceptionally high temperatures and low precipitation during June, July and beginning of August (Fig. S1). Weather conditions were slightly more extreme in 2019 compared to 2020 . Soil matric potentials declined drastically between $\mathrm{BBCH} 19$ (9 leave stage) and $\mathrm{BBCH} 59$ (flowering), reducing plant available water to close to zero ( $\mathrm{pF} 4.2$ ) at flowering over the whole soil profile for all treatments, except S_rth3 (Fig. 1). In 2019, plants showed severe drought stress symptoms (leaf rolling) and deviation of actual from potential transpiration in the following temporal sequence: L_WT (DAP 82) < L_rth3 (DAP 91) < S_WT (DAP 94) < S_rth3 (DAP 94) (Jorda et al. in preparation). In 2020, deviation of actual from potential transpiration was observed slightly later in the season and in general earlier for the wild-type as compared to rth3 (L_WT (DAP 92) < S_WT (DAP 94) < L_rth3 (DAP114) < S_rth3 (DAP 138).

\section{Shoot growth, shoot nutrient concentrations, content and nutrient uptake}

During the early growth phase from germination to four leaves stage $(\mathrm{BBCH} 14)$ it was possible to compensate for the initial differences in nutrient supply through differential fertilisation of the two substrates. By this approach, the tissue concentration in the young unfolded leaves was not influenced ( $P$, $\mathrm{N}$ ) or only slightly influenced (K) by the substrate (Fig. 2). As intended, the plant nutrient status was below 
adequate supply, especially of $\mathrm{P}$ and $\mathrm{K}$. During further plant development (BBCH 19, BBCH 59), however, nutrient deficiency increased more in the sand treatments compared to the loam treatments. For tissue concentrations, no significant influence of genotype was observed for any of the elements at any time during plant development, except for $\mathrm{N}$ at $\mathrm{BBCH} 14$ and $\mathrm{BBCH}$ 59. In contrast to the tissue concentrations, the production of shoot biomass was significantly influenced by the genotype (Fig. 3). In both years and at all growth stages, the wild-type had a higher shoot dry weight than the mutant with defective root hairs. The substrate had a significant influence on shoot growth at $\mathrm{BBCH} 19$ and 59, with the differences decreasing towards maturity (BBCH 83). In agreement with the dry weight of the shoots, the P content of the shoots (product of dry weight and concentration of shoot tissue) was significantly influenced by the genotype at all growth stages (Fig. 4a). Especially in loam, the wild-type showed a higher P content than $r$ th3, which was reflected in a significant influence of substrate and a significant interaction term at $\mathrm{BBCH}$ 19 and $\mathrm{BBCH}$ 59. $\mathrm{P}$ uptake per unit root surface area was also higher in the wild-type compared to rth 3 in loam, but not in sand (Fig. 4b). In general, the P uptake was higher in loam than in sand.

\section{Root traits}

Unlike shoot dry mass, root length density across all depths was significantly higher in sand than in loam at all growth stages except for BBCH 14 (Fig. 5). At BBCH 14 there was only a tendency for higher values for sand compared to loam; the values were generally low and the variability between the samples high. Genotype also had a significant effect on root length density: In the three depths, wild-type root length density was higher than that of $r$ th 3 at $\mathrm{BBCH} 59$ and $\mathrm{BBCH} 83$ in sand. The differences between genotypes were smaller than those caused by substrate. In general, root length densities were higher in the top $20 \mathrm{~cm}$ in 2020 at BBCH 59 and 83. In 2020, it should be noted that the root length densities for sand were higher than for loam, despite the correction for dead roots. This correction was not necessary for loam as roots decomposed quicker in this substrate (see Fig. S2 for original values).

In 2019, the first year of plant growth on the newly established, homogenized plots, substrate had a significant impact on mean root diameter, with larger diameters observed for sand treatments as compared to loam treatments (Fig. 6). Genotype had a smaller impact on diameter, resulting in slightly larger values for $r$ th 3 as compared to the wild-type. Significantly higher values for $r$ th 3 than wild-type were observed e.g. in 0-20 cm depth at $\mathrm{BBCH} 19$ and $\mathrm{BBCH} 59$ in sand during 2019, but in both substrates in 2020. Similar effects by genotype were observed at all depths.

In 2020, mean root diameters across all treatments were larger compared to 2019 (313 $\pm 17 \mu \mathrm{m}$ versus $248 \pm 3 \mu \mathrm{m}$ ). For 0-20 cm depth and partly for the lower depths the marked impact of substrate had vanished, whereas differences between genotypes became stronger in 0-20 and 20-40 cm depths.

Differences in mean root diameter between treatments were reflected in a shift in the ratio of cortex width in relation to the width of the vascular bundle (Fig. 7). Sand treatments had a higher ratio than loam in the $20-40 \mathrm{~cm}$ depth at $\mathrm{BBCH} 19$ and 59 for both years. Interestingly, root segments investigated likewise 
showed differences in aerenchyma formation, the latter being more marked for the loam treatment as compared to the sand treatments.

Mycorrhizal colonisation was observed as early as at $\mathrm{BBCH} 14$ and it reached values in the range of 40 to $60 \%$ at BBCH 59 in 0-20 cm depth (Fig. 8). Colonisation rate increased by maize age and reduced by soil depth $(p<0.05)$. After no differences between substrates at BBCH 14, higher level of colonisation in loam than sand at BBCH 19 changed to a reversed pattern at BBCH 59 (Fig. 8). The impact of genotype was not significant.

The root hair mutant $r$ th 3 consistently showed only few roots segments $(<20 \%)$ with some up to $50 \mu \mathrm{m}$ extended hair like structures, but mostly only bulged epidermal cells, while $50-90 \%$ of wild-type root segments showed dense populations of elongated root hairs (Fig. S3).

\section{Root to shoot ratio and water use efficiency}

The different relevance of the factors substrate and genotype for shoot and root growth is reflected in the root to shoot ratio (Fig. 9). Substrate as well as genotype showed a significant impact on root to shoot ratio, with higher values for sand than loam and higher values for the root hair mutant $r$ th 3 than the wildtype. In line with what is expected during maize ontogeny, root to shoot ratios decreased with plant age. On average values in 2020 were $30 \%$ higher compared to 2019 .

Water use efficiency, expressing water loss from the soil profile (transpiration plus evaporation) in relation to biomass produced during the respective period, increased with time. This is because the share of unproductive evaporation in relation to total water consumption decreased (Fig. 10, Jorda et al. in preparation). Water use efficiency was always higher for the wild-type as compared to the root hair mutant rth3. This was observed irrespective of substrate and year and is in line with observations in column experiments under well-watered conditions (Fig. 10, inset).

\section{Discussion}

For the discussion part of our study, we will attempt to answer our original hypotheses stated in the introduction. The overall pattern emerging is conceptualized in Figure 11.

Do hairs matter at field scale for biomass production and nutrient uptake, in particular for loam as mobility of nutrients is low?

The relevance of root hairs for plant nutrient acquisition has been reviewed in depth by Jungk (2001) and was recently revisited by Bienert et al. (2021) providing an overview on the location of respective transporters for all essential plant nutrients. In line with literature, the observed differences in shoot biomass development between the wild-type and the root hair mutant corresponded to differences in shoot $\mathrm{P}$ content, and for the substrate loam that was accompanied by higher $\mathrm{P}$ uptake per unit root surface. Such higher normalized $P$ uptake could reflect the expected upregulation of $P$ transporters in the hairs under P deficiency (Bienert et al. 2021). However, they could also simply be explained by increased 
surface area for uptake provided by the hairs, or the decrease in path length required for $\mathrm{P}$ diffusion across the rhizosphere (Leitner et al. 2010). The latter is of particular relevance for soils with low $P$ mobility and would explain why differences in uptake rates were not observed in sand, not even for the early growth stages. In sand neither $\mathrm{P}$ uptake nor $\mathrm{P}$ content differed between genotypes. The differences in shoot biomass are potentially explained by the higher investment of the root hair mutant into root growth (reflected in root to shoot ratio), which might have enabled similar $\mathrm{P}$ uptake. The $\mathrm{P}$ concentration in young leaves indicate that $P$ availability was lower for sand during the later growth stages $(B B C H 19$, $\mathrm{BBCH}$ 59). For sand, unlike loam, initial plant available $P$ concentration and total $P$ concentration (Bilyera et al. 2021; Vetterlein et al. 2021) have been very low (8.3 and $53 \mathrm{mg} \mathrm{kg}^{-1}$ respectively). Thus, plants in the sand plots relied to a larger extent on surface-applied fertiliser, and when this was depleted or no longer available due to drying of the topsoil, the only viable adaptation strategy was to tap into a larger soil volume (Fig. 11). In loam, initial plant available P concentration was four times higher than in sand (32.7 mg kg-1), so it was expected that investments in exploitation strategies such as hairs and alteration of rhizosphere chemistry by release of organic acid anions or acid phosphatases would return more $\mathrm{P}$ to the plants. This was actually the case, as both genotypes extracted more P (and K, Fig. S4) from the loam plots then was applied as fertilizer (Tab. S3). Our initial hypothesis 'hairs matter at field scale for biomass production and nutrient uptake, in particular for loam as mobility of nutrients is low' was confirmed. For sand the results are explained by higher mobility of fertilizer $P$ during the initial growth stages as compared to loam. For the later growth stages, the results are explained by the required shift to an exploration strategy which altered the $\mathrm{C}$ budget (root to shoot ratio) more than the return in $\mathrm{P}$. Differences in root hair development between substrates for the wild-type could provide an alternative explanation for the observed differences between sand and loam. Marin et al. (2020) report longer root hairs for clay loam compared to sandy loam across all barley genotypes investigated. Note that root hair length was not measured in our field experiment, but in the twin laboratory experiment with the same treatments no differences in root hair length between the two substrates were observed (Lippold et al. 2021).

Do root hairs contribute to water acquisition by plants, especially under drought stress, and is this effect more important in sandy substrates?

In both years precipitation was exceptionally low compared to the long-term average for the region and hence drought stress developed as the growing season advanced. As described above, up to growth stages BBCH 14 and BBCH 19, differences in shoot growth between genotypes can be explained by the availability of $\mathrm{N}, \mathrm{P}$ and $\mathrm{K}$. The strong decline in plant available water between $\mathrm{BBCH} 19$ and 59, in particular in the topsoil (Fig. 1), did not only render fertilizer less available in the topsoil, but resulted in visible symptoms of drought stress (leaf rolling) and in an increase of mechanical impedance from 0.5 $\mathrm{MPa}$ to $>2.2 \mathrm{MPa}$ (Rosskopf et al. submitted). We observed an earlier onset of drought stress for the wildtype in both years, which was related to larger shoot size and hence water requirement (potential transpiration) at that specific time point. Wild-type in loam suffered particularly strongly from drought stress and did not show any biomass increase past BBCH 59 in 2019. Hence, despite significant differences in shoot biomass development between genotypes the cumulative soil water extraction for

Page $12 / 29$ 
the whole growing season, normalized to soil surface area was similar between the wild-type and rth3 (Jorda et al. in preparation). However, when cumulative water extraction is normalised to shoot dry weight, we observed higher water use efficiency of wild-type as compared to the root hair mutant. Higher water use efficiency could be explained by a more sensitive regulation of stomata in response to drought (Benešová et al. 2012) or by a more inefficient use of the assimilated carbon by the root hair mutant. The latter could be related to higher maintenance respiration (Earl et al. 2012) or root exudation (Santangeli et al. in preparation) paired with an already larger investment into roots relative to shoot size. Even when the root biomass itself is accounted for in the calculation of water use efficiency (Fig. 10b) the discrepancy between genotypes remained and was observed in both years. Based on the literature (Carminati et al. 2017b), hairs were expected to improve root-soil contact and increase the apparent root radius. Both mechanisms would help avoid or delay steep water potential gradients around the roots, thus allowing a longer maintenance of soil water extraction and thus a more thorough utilisation of plant-available soil water. These mechanisms would not be expected to alter water use efficiency per se, because they would increase water uptake and biomass production at the same time. More importantly, the relevance of this bridging effect has only been experimentally proven for barley, but has not been confirmed for maize in dedicated laboratory studies with the same substrates and genotypes (Cai et al. 2021). Simulation of plant water relations for the present field study with Hydrus 1D matched measured results for soil water extraction, transpiration flux and plant water potential without requiring a genotype specific parametrisation of root hydraulic conductivity. The model runs showed that root length density never limited water extraction from the soil at the rate required by the evapotranspiration demand. In relation to shoot size and their transpiration needs, there were always enough roots to exploit soil water down to permanent wilting point (Jorda et al. in preparation). Note that the model used for the simulations does not explicitly account for the conductivity/resistance of the rhizosphere.

Currently it cannot be ruled out that the observed differences in water use efficiency between genotypes might be the result of a pleiotropic effect of the rth 3 mutation. Differences in water use efficiency are systematic, as they were not only observed in the field or upon water limitation, but are likewise reported for laboratory experiments under well-watered conditions (Fig. 10). Further studies addressing constitutive or inducible differences in stomata number and photosynthetic water use efficiency are currently conducted. Plasma membrane aquaporin expression in roots is not affected by maize genotype, and the changes in transcript abundancies due to substrate and drought stress at BBCH59 are conserved between the wild-type and $\mathrm{rth} 3$ roots (Ganther et al. in preparation). Alternatively, if root hairs function as sensors for drought stress as recently suggested by Kwasniewski et al. (2016), this could also explain the observed differences.

Is the root hair mutant rth3 showing plasticity in other root traits to compensate for the lower surface? What is the relevance for rhizodeposition /carbon partitioning?

\section{Root traits}


Root dry weight and related root to shoot ratio development over time as well as absolute values were well within the range of values reported by Amos and Walters (2006) and Ordóñez et al. (2020) reviewing published data for maize ( $n=45$ and 125, respectively). Maximum root biomass production is expected at tassel emergence (BBCH 59) or shortly thereafter and root to shoot ratio decreases as plants grow and remains nearly constant during the reproductive growth stages (Amos and Walters 2006). This was the case for our root growth data (Fig. 5) and root to shoot ratios (Fig. 9) in both years. The selection of constant distance of $10 \mathrm{~cm}$ to the base of the plant for all sampling time points was a suitable compromise between overestimation of early root growth when sampling under the plant and overestimation for the later growth stages when sampling at mid-distance between the rows (Gajri et al. 1994). It proved important that sampling was conducted in three depth intervals down to $60 \mathrm{~cm}$ as the general assumption of root mass or length decreasing with depth, with the majority of roots located in the top 20 to $30 \mathrm{~cm}$ ((Amos and Walters 2006) and citations therein) did not hold true under the encountered environmental conditions (drought, homogeneous substrate).

\section{Root to shoot ratio}

Our values at $\mathrm{BBCH} 59$ and 83 are within the data range of 0.02 to 0.4 for maize derived from a metaanalysis of 125 datasets provided by Ordóñez et al. (2020). This paper indicates that maize as compared to soybean has a very high plasticity in root to shoot ratio and that shoot biomass cannot be used to estimate root biomass. This applies even more to the estimation of root length. This plasticity is reflected in significant differences in root to shoot ratios between our treatments and the different impact of drivers (substrate, genotype) on shoot biomass (Fig. 3) versus root biomass (not shown) or root length density (Fig. 5).

\section{Root length density}

The mean values for root length density $(n=17)$ reported for the reproductive phase of $1.8( \pm 0.15) \mathrm{cm}$ $\mathrm{cm}^{-3}$ (Amos and Walters 2006; Ordóñez et al. 2020) is higher than the values we observed for loam, but lower than those measured for sand. Root length density depth profiles serve as a proxy for root architecture at field scale. For the field, as in the corresponding laboratory experiments (Lippold et al. 2021), no change in root length density profiles in response to the lack of root hairs could be found. This is in contrast to what has been suggested for other root hairless maize (rth2, (Klamer et al. 2019)) or barley mutants (brb, (Dodd and Diatloff 2016). The substrate, in turn, caused a pronounced and unexpected difference in root length density, which was accompanied by a shift in root length density across root diameter classes (Fig. S5). The larger root length densities for sand can in part be explained by the lower content in plant available nutrients. This is valid except for the surface where fertilizer has been applied. Progressive soil drying shifted root growth to larger soil depths. The fact that this shift was more pronounced for loam than sand might again be related to the more uneven nutrient distribution in sand. Higher root lengths in the coarser substrate were also observed by Marin et al. (2020) for barley comparing sandy loam and clay loam. 


\section{Root diameter}

The higher share of root length in the smallest root diameter class $(0-100 \mu \mathrm{m})$ for loam as compared to sand is reflected in the lower root mean diameters (Fig. 6). Larger share of fine roots is typically reported for nutrient rich patches in heterogeneous soils or for substrates with low availability of nutrients in general (Hodge 2004; Strock et al. 2018; Vejchasarn et al. 2016). However, in the present experiment nutrients were homogeneously distributed except for the top centimetres affected by surface applied fertilizer. Plant available nutrient concentrations below the fertilizer affected surface were higher in loam than in sand. Similar differences in root diameters between the substrates have also been observed for the twin laboratory experiment for which fertilizer was homogeneously mixed into the substrate and similar amounts of plant available nutrients were present (Lippold et al. 2021). Doubling the amount of fertilizer in the laboratory experiments had no impact on root diameters (data not shown). Hence it is unlikely that nutrients are responsible for the observed differences in diameter. Increases in root diameters have most frequently been observed in response to increases in soil penetration resistance (Bengough et al. 2006; Correa et al. 2019). For the laboratory experiment penetration resistance was in the range of 0.1 to $0.5 \mathrm{MPa}$ for sand and loam respectively (Rosskopf et al. 2021). For samples collected from the field values ranged from 0.5 to $2.2 \mathrm{MPa}$ with water potential decreasing from -3 to $-50 \mathrm{kPa}$ with no significant differences between sand and loam in neither of the two depths investigated (Rosskopf et al. submitted). Not only there was no difference in penetration resistance between the substrates within the measured range of soil matric potential, below which the values only fell after BBCH 19 in 2019, but there was also no associated decrease in root growth (root length), which is typically observed when soil penetration resistance affects roots (Correa et al. 2019).

\section{Arbuscular mycorrhiza (AM) formation}

We expected that the rth3 plants would show higher colonisation levels, especially as mycorrhiza formation can actually compensate for the loss of root hairs in the rth 3 mutant. By implementing an AMF inoculation experiment, $\mathrm{Ma}$ et al. (2021) showed that the positive effects of mycorrhiza formation on plant growth and $\mathrm{P}$ acquisition in rth3 were 1.5- to 3.9-fold greater than in the wild-type, and AMF colonisation complemented growth and $\mathrm{P}$ acquisition defects of the mutant. Interestingly, mycorrhizas also effectively substituted root hairs in P uptake in barley (Jakobsen et al. 2005). Our data suggest that either the $r$ th 3 maize was not $P$ limited but instead limited in mineral nutrients whose uptake is not dependent on mycorrhizal fungi (Kothari et al. 1990; Liu et al. 2000), or it was not able to allocate enough carbon to the mycorrhizal fungi to support a higher colonisation of the roots than observed (Fellbaum et al. 2012), and support the mycorrhiza dependent nutrient uptake. In general, availability of $P$ in the soil in part determines how maize is colonised and how it responds to mycorrhiza colonization under field conditions. In this field experiment, the low levels of available P should support AM colonisation of maize roots.

In summary, we cannot confirm our hypothesis that rth 3 shows plasticity to compensate for the lower surface induced by the lack of root hairs, apart from a higher investment in root growth relative to shoot 
growth (Fig. 11). However, both genotypes did show strong plasticity of root traits in response to substrate. While higher root length density in sand as compared to loam is probably brought about by the lower content of plant available nutrients (Gao et al. 2015; Hodge 2004), this does not explain the increase in mean root diameter observed for sand. Higher root length density combined with an increase in diameter and a smaller share of aerenchyma added up to a substantially larger input of carbon for sand as compared to loam which is expected to impact carbon sequestration over the years. Interestingly the observation of slower root degradation in sand is in line with observations from a laboratory experiment on biopore recycling for which X-ray CT revealed likewise that roots in loam were completely degraded after 78 days while still present in sand after 216 days (Phalempin et al. submitted).

\section{What explains the texture related differences in root traits beyond differences in nutrient supply?}

It is a unique feature of our experiment based on artificially established soil profiles, that we can compare the effect of texture on root growth in the field under identical environmental conditions. Other studies comparing different soil types or texture had to do so by establishing experiments at different sites or at least different areas within large sites (Chassot et al. 2001; Dwyer et al. 1988; Marin et al. 2020; Qin et al. 2005; Sene et al. 1985).

There is a number of studies which investigated root traits for soils differing in texture, however, most of these studies did either (i) not report information on root diameter, (ii) could explain observed increases in root diameter by increasing mechanical resistance/compaction, or (iii) could not separate the effect of texture from differences in environmental conditions and management (precipitation, temperature, nutrient availability, soil cultivation) (Table S4 and citations therein). Surprisingly few studies have addressed explicitly the impact of particle size distribution (Anderson et al. 2007; Rogers et al. 2016; Warnaars and Eavis 1972) or the shape of particles (Lipiec et al. 2016) on root diameter. Rogers et al. (2016) found no consistent pattern among different rice genotypes; some did show an increase in root diameter with coarser substrate texture. Warnaars and Eavis (1972) found a decrease in specific root length, used as a surrogate for root diameter, with increasing particle sizes and likewise Anderson et al. (2007) reported the share of fine roots to decrease with increase in soil sand fraction. Larger root diameters in sand as compared to loam were observed throughout all growth stages and depths in 2019 when plants grew into the homogenized soil structure for the first time. For this reason it is unlikely that differences in root diameters can be explained by substrate specific shifts between root types (brace, crown, seminal root axis and respective laterals). In addition, the differences in diameter corresponded to different ratios or cortex width to vascular bundle width measured for main root axis. This would not be expected if the differences would be due to a larger share of fine lateral roots. Coarser particles or aggregates will show a lower contact area with a smooth surface such as the root surface as compared to fine particles. This was demonstrated by Schmidt et al. (2012) for maize roots growing in aggregate fractions of 4-2, 2-1, 1-0.5 and $<0.5 \mathrm{~mm}$. Reduced root-soil contact is potentially unfavourable for nutrient and water uptake and might trigger adaption mechanisms to compensate for this. Increasing root 
diameter could be such an adaption mechanism but one associated with high carbon costs (Lynch and Ho 2005). Currently the mechano-sensing of roots is poorly understood (Dupuy et al. 2018; Monshausen and Gilroy 2009). Roots can show responses to touch or impermeable mechanical barriers by changes in cell division patterns, growth direction, cell differentiation and gene expression. Changes in pressure at the plant cell surface are signalled by mechanosensitive ion channels and kinases to the microtubule cytoskeleton, and lead to altered cytoskeletal architecture and reinforcement of the cell wall (Hamilton et al. 2015; Tang et al. 2021).

Dupuy et al. (2018) recently suggested re-visiting micromechanics of rooting development in soil by considering recent advances in granular matter physics. They pointed out that the 'classical mechanics of continua' is ill-equipped to explain the links between soil heterogeneity and stochasticity of plant development. They argue that this is of particular relevance for medium grained soils; here roots can displace individual particles from the soil, but the forces exerted by each of the particles can also influence the course of root development. The latter is not reflected in the measurement of mechanical impedance (Rosskopf et al. 2021). Crucial for this type of concept is the size aspect ratio between root's diameter and typical length scale of soil heterogeneity (particle size) (Kolb et al. 2017). The increase of root diameter observed in sand can be interpreted as an attempt to maintain an optimal size aspect ratio.

The root phene 'increased root diameter' can be induced by ethylene as such, i.e. even in systems without soil or pressure (Sarquis et al. 1991). Pandey et al. (2021) recently concluded from their study that ethylene acts as an early warning signal for roots to avoid compacted soil and that the mechanism is related to altered gas diffusion in the rhizosphere. Hence the questions arise whether ethylene is also the signalling substance in our systems, and which mechanisms may result in increased ethylene concentrations in the rhizosphere. Root-soil contact (Schmidt et al. 2012), bulk density gradients in the rhizosphere (Phalempin et al. 2021) as well as gas diffusion per se differ between sand and loam due to differences in porosity and soil water content.

Sensing of contact has been demonstrated for root tips (Massa and Gilroy 2003), and is very likely related to root cap-dependent ethylene emission (Dreyer and Edelmann 2018). Sensing of contact points along the root surface could thus also be related to ethylene production and or distribution and release. Hence, as an alternative to differences in ethylene diffusion between substrates, we suggest that ethylene production might be triggered specifically in sand related to sensing of contact. The role of hairs in this respect is unclear. They might be involved in sensing contact, but they have also been reported to respond to increased ethylene concentrations, i.e. increased root hair length and numbers (Feng et al. 2017).

\section{Conclusion And Outlook}

Genotypes differed in shoot growth with differences being larger in loam than sand in line with hypothesis 1 (Fig. 11). For the early growth stages, as long as topsoil was moist, exploitation strategy related to the presence of hairs might have been successful to tap the applied fertilizer. For later growth stages, as drought developed, roots had to explore the entire soil volume in particular for sand, being 
overall low in plant available nutrients. Root architecture was shaped primarily by the need to access nutrients with increasing drought progressively altering the volume which could be successfully explored for nutrients. Obviously exploitation strategy related to hairs ranked second under these conditions, in particular in sand. This explains the high root length density in sand associated with high root to shoot ratio. The larger root diameter in sand than in loam, which was also observed in twin laboratory experiments under well-water conditions for early growth stages was not related to the differences in mechanical resistance between substrates. We hypothesize that this is a general phenomenon in coarse textured substrates related to the need of optimising root-soil contact. The underlying mechanisms should be explored in future dedicated experiments. Higher root length density along with larger root diameters resulted in higher carbon input in sand than in loam. The impact of altered carbon budgets on microbial community composition and microbial activity as well as soil structure formation and stability is under investigation.

\section{Declarations}

\section{Acknowledgements}

For supporting the maintenance of the field experiment and the sampling events we would like to thank Sebastian Häusler, Eric Braatz, Anne-Sophie Wachter, Antonia Geyer, Franziska Busch, Jakob Streuber, Julius Schäfer, Oskar Wolgramm, Stephanie Pilous, Tanja Knauerhase, Toni Fahrenkampf, Bernd Apelt, Sylvia Schmögner. Without their care and patience this study would not have been possible. We would like to acknowledge the support from Bad Lauchstädt field station (Ines Merbach, Konrad Kirsch, Sven Meyer, Sabine Straßenburg, Steffı Wagner, Thomas Bienert, Birgit Sawall).

Further, we acknowledge Dr. Yudelsy Tandron Moya for performing the ICP-OES analysis (IPK Gatersleben). Seeds of the maize mutant $r$ th3 were provided by Caroline Macron and Frank Hochholdinger (University Bonn).

\section{Funding}

This project was carried out in the framework of the priority programme 2089

"Rhizosphere spatiotemporal organisation - a key to rhizosphere functions" funded by DFG, German Research Foundation (project number 403801423).

\section{Competing Interest}

The authors have no relevant financial or non-financial interests to disclose

\section{Author Contributions}


All authors contributed to the study conception and design. Material preparation, data collection and analysis were performed by Doris Vetterlein, Steffen Schlüter and Mika Tarkka. The first draft of the manuscript was written by Doris Vetterlein and all authors commented on previous versions of the manuscript. All authors read and approved the final manuscript.

\section{Data availability}

The datasets generated during and/or analysed during the current study are available from the corresponding author on reasonable request.

\section{References}

1. Amos B, Walters D (2006) Maize root biomass and net rhizodeposited carbon: an analysis of the literature. Soil Sci Soc Am J 70:1489-1503

2. Anderson T, Starmer W, Thorne M (2007) Bimodal root diameter distributions in Serengeti grasses exhibit plasticity in response to defoliation and soil texture: implications for nitrogen uptake. Funct Ecol 21:50-60

3. Bates TR, Lynch JP (2001) Root hairs confer a competitive advantage under low phosphorus availability. Plant Soil 236:243-250

4. Benešová $M$, Hola $D$, Fischer $L$, Jedelský $P L$, Hnilička F, Wilhelmová $N$, Rothova $O$, Kočová $M$, Prochazkova D, Honnerova J (2012) The physiology and proteomics of drought tolerance in maize: early stomatal closure as a cause of lower tolerance to short-term dehydration? PLoS ONE 7:e38017

5. Bengough AG, Bransby MF, Hans J, McKenna SJ, Roberts TJ, Valentine TA (2006) Root responses to soil physical conditions; growth dynamics from field to cell. J Exp Bot 57:437-447

6. Bergmann W (1986) Farbatlas Ernährungsstörungen bei Kulturpflanzen: Visuelle und analytische Diagnose. Fischer Verlag, Jena

7. Bienert MD, Werner LM, Wimmer MA, Bienert GP (2021) Root hairs: the villi of plants. Biochem Soc Trans 49:1133-1146

8. Bilyera N, Hummel C, Daudin G, Santangeli M, Zhang X, Santner J, Lippold E, Schlüter S, Bertrand I, Wenzel W (2021) Co-localised phosphorus mobilization processes in the rhizosphere of field-grown maize jointly contribute to plant nutrition. Soil Biol Biochem 165:108497

9. Bleiholder H, Weber E, Lancashire P, Feller C, Buhr L, Hess M, Wicke H, Hack H, Meier U, Klose R (2001) Growth stages of mono-and dicotyledonous plants, BBCH monograph. Federal Biological Research Centre for Agriculture and Forestry, Berlin/Braunschweig, Germany

10. Cai G, Carminati A, Abdalla M, Ahmed MA (2021) Soil textures rather than root hairs dominate water uptake and soil-plant hydraulics under drought. Plant Physiol 187:858-872

11. Carminati A, Benard P, Ahmed M, Zarebanadkouki M (2017a) Liquid bridges at the root-soil interface. Plant Soil 417:1-15 
12. Carminati A, Passioura JB, Zarebanadkouki M, Ahmed MA, Ryan PR, Watt M, Delhaize E (2017b) Root hairs enable high transpiration rates in drying soils. New Phytol 216:771-781

13. Chassot A, Stamp P, Richner W (2001) Root distribution and morphology of maize seedlings as affected by tillage and fertilizer placement. Plant Soil 231:123-135

14. Chimungu JG, Brown KM, Lynch JP (2014) Large root cortical cell size improves drought tolerance in maize. Plant Physiol 166:2166-2178

15. Correa J, Postma JA, Watt M, Wojciechowski T (2019) Soil compaction and the architectural plasticity of root systems. J Exp Bot 70:6019-6034

16. Dodd IC, Diatloff E (2016) Enhanced root growth of the brb (bald root barley) mutant in drying soil allows similar shoot physiological responses to soil water deficit as wild-type plants. Funct Plant Biol 43:199-206

17. Dreyer J, Edelmann HG (2018) Root cap-mediated evaluation of soil resistance towards graviresponding roots of maize (Zea mays L.) and the relevance of ethylene. Ann Botany 122:791800

18. Dupuy LX, Mimault M, Patko D, Ladmiral V, Ameduri B, MacDonald MP, Ptashnyk M (2018) Micromechanics of root development in soil. Current Opinion in Genetics and Development 51:18-25

19. Dwyer L, Stewart D, Balchin D (1988) Rooting characteristics of corn, soybeans and barley as a function of available water and soil physical characteristics. Can J Soil Sci 68:121-132

20. Earl HJ, Liu W, Bowley SR, Tollenaar M (2012) Effects of abiotic stress on respiratory carbon loss of two maize (Zea mays L.) inbred lines and their hybrid during silking and grain-filling. Crop Sci 52:1795-1802

21. Fellbaum CR, Gachomo EW, Beesetty Y, Choudhari S, Strahan GD, Pfeffer PE, Kiers ET, Bücking H (2012) Carbon availability triggers fungal nitrogen uptake and transport in arbuscular mycorrhizal symbiosis. Proceedings of the National Academy of Sciences 109: 2666-2671

22. Fitter A (1987) An architectural approach to the comparative ecology of plant root systems. New Phytol 106:61-77

23. Gahoonia TS, Nielsen NE (1997) Variation in root hairs of barley cultivars doubled soil phosphorus uptake. Euphytica 98:177-182

24. Gahoonia TS, Nielsen NE (2004) Root traits as tools for creating phosphorus efficient crop varieties. Plant Soil 260:47-57

25. Gajri P, Arora V, Kumar K (1994) A procedure for determining average root length density in row crops by single-site augering. Plant Soil 160:41-47

26. Gao K, Chen F, Yuan L, Zhang F, Mi G (2015) A comprehensive analysis of root morphological changes and nitrogen allocation in maize in response to low nitrogen stress. Plant, Cell Environ 38:740-750

27. Gebauer L, Bouffaud M-L, Ganther M, Yim B, Vetterlein D, Smalla K, Buscot F, Heintz-Buschart A, Tarkka MT (2021) Soil texture, sampling depth and root hairs shape the structure of ACC deaminase 
bacterial community composition in maize rhizosphere. Front Microbiol 12:616828

28. George TS, Brown LK, Ramsay L, White PJ, Newton AC, Bengough AG, Russell J, Thomas WT (2014) Understanding the genetic control and physiological traits associated with rhizosheath production by barley (Hordeum vulgare). New Phytol 203:195-205

29. Hamilton ES, Schlegel AM, Haswell ES (2015) United in diversity: mechanosensitive ion channels in plants. Annu Rev Plant Biol 66:113-137

30. Hochholdinger F, Wen TJ, Zimmermann R, Chimot-Marolle P, Da Costa e Silva O, Bruce W, Lamkey KR, Wienand U, Schnable PS (2008) The maize (Zea mays L.) roothairless3 gene encodes a putative GPIanchored, monocot-specific, COBRA-like protein that significantly affects grain yield. Plant J 54:888898

31. Hochholdinger F, Yu P, Marcon C (2018) Genetic control of root system development in maize. Trends Plant Sci 23:79-88

32. Hodge A (2004) The plastic plant: root responses to heterogeneous supplies of nutrients. New Phytol $162: 9-24$

33. Hodge A (2006) Plastic plants and patchy soils. J Exp Bot 57:401-411

34. Jakobsen I, Chen B, Munkvold L, Lundsgaard T, ZHU YG (2005) Contrasting phosphate acquisition of mycorrhizal fungi with that of root hairs using the root hairless barley mutant. Plant Cell Environ 28:928-938

35. Jaramillo RE, Nord EA, Chimungu JG, Brown KM, Lynch JP (2013) Root cortical burden influences drought tolerance in maize. Ann Botany 112:429-437

36. Jungk A (2001) Root hairs and the acquisition of plant nutrients from soil. J Plant Nutr Soil Sci 164:121-129

37. Klamer F, Vogel F, Li X, Bremer H, Neumann G, Neuhäuser B, Hochholdinger F, Ludewig U (2019) Estimating the importance of maize root hairs in low phosphorus conditions and under drought. Ann Botany 124:961-968

38. Kolb E, Legué V, Bogeat-Triboulot M-B (2017) Physical root-soil interactions. Phys Biol 14:065004

39. Kothari S, Marschner H, George E (1990) Effect of VA mycorrhizal fungi and rhizosphere microorganisms on root and shoot morphology, growth and water relations in maize. New Phytol 116:303-311

40. Kwasniewski M, Daszkowska-Golec A, Janiak A, Chwialkowska K, Nowakowska U, Sablok G, Szarejko I (2016) Transcriptome analysis reveals the role of the root hairs as environmental sensors to maintain plant functions under water-deficiency conditions. J Exp Bot 67:1079-1094

41. Leitner D, Klepsch S, Ptashnyk M, Marchant A, Kirk G, Schnepf A, Roose T (2010) A dynamic model of nutrient uptake by root hairs. New Phytol 185:792-802

42. Lipiec J, Siczek A, Sochan A, Bieganowski A (2016) Effect of sand grain shape on root and shoot growth of wheat seedlings. Geoderma 265:1-5 
43. Lippold E, Phalempin M, Schlüter S, Vetterlein D (2021) Does the lack of root hairs alter root system architecture of Zea mays? Plant Soil 467:267-286

44. Liu A, Hamel C, Hamilton R, Ma B, Smith D (2000) Acquisition of $\mathrm{Cu}, \mathrm{Zn}, \mathrm{Mn}$ and Fe by mycorrhizal maize (Zea mays L.) grown in soil at different $P$ and micronutrient levels. Mycorrhiza 9:331-336

45. Lynch JP (2013) Steep, cheap and deep: an ideotype to optimize water and N acquisition by maize root systems. Ann Botany 112:347-357

46. Lynch JP, Ho MD (2005) Rhizoeconomics: carbon costs of phosphorus acquisition. Plant Soil 269:45-56

47. Lynch JP, Strock CF, Schneider HM, Sidhu JS, Ajmera I, Galindo-Castañeda T, Klein SP, Hanlon MT (2021) Root anatomy and soil resource capture. Plant Soil 466:21-63

48. Ma X, Li X, Ludewig U (2021) Arbuscular mycorrhizal colonization outcompetes root hairs in maize under low phosphorus availability. Ann Botany 127:155-166

49. Marin M, Feeney D, Brown L, Naveed M, Ruiz S, Koebernick N, Bengough A, Hallett P, Roose T, Puértolas J (2020) Significance of root hairs for plant performance under contrasting field conditions and water deficit. Ann Botany 128:1-16

50. Massa GD, Gilroy S (2003) Touch modulates gravity sensing to regulate the growth of primary roots of Arabidopsis thaliana. Plant J 33:435-445

51. McGonigle T, Miller M, Evans D, Fairchild G, Swan J (1990) A new method which gives an objective measure of colonization of roots by vesicular-arbuscular mycorrhizal fungi. New Phytol 115:495501

52. Miguel MA, Postma JA, Lynch JP (2015) Phene synergism between root hair length and basal root growth angle for phosphorus acquisition. Plant Physiol 167:1430-1439

53. Monshausen GB, Gilroy S (2009) The exploring root-root growth responses to local environmental conditions. Curr Opin Plant Biol 12:766-772

54. Morris EC, Griffiths M, Golebiowska A, Mairhofer S, Burr-Hersey J, Goh T, Von Wangenheim D, Atkinson B, Sturrock CJ, Lynch JP (2017) Shaping 3D root system architecture. Curr Biol 27:R919R930

55. Nestler J, Keyes SD, Wissuwa M (2016) Root hair formation in rice (Oryza sativa L.) differs between root types and is altered in artificial growth conditions. J Exp Bot 67:3699-3708

56. Nestler J, Wissuwa M (2016) Superior root hair formation confers root efficiency in some, but not all, rice genotypes upon $\mathrm{P}$ deficiency. Front Plant Sci 7:1935

57. Ordóñez RA, Archontoulis SV, Martinez-Feria R, Hatfield JL, Wright EE, Castellano MJ (2020) Root to shoot and carbon to nitrogen ratios of maize and soybean crops in the US Midwest. Eur J Agron 120:126130

58. Pandey BK, Huang G, Bhosale R, Hartman S, Sturrock CJ, Jose L, Martin OC, Karady M, Voesenek LA, Ljung K (2021) Plant roots sense soil compaction through restricted ethylene diffusion. Science $371: 276-280$ 
59. Phalempin M, Lippold E, Vetterlein D, Schlüter S (2021) Soil texture and structure heterogeneity predominantly governs bulk density gradients around roots. Vadose Zone J 20:e20147

60. Phalempin M, Landl M, Wu G-M, Schnepf A, Vetterlein D, Schlüter S Maize root-induced biopores do not influence root growth of subsequently grown maize plants in well aerated, fertilized and repacked soil columns. Soil and Tillage Research: submitted STILL-D-21-01137

61. Postma JA, Lynch JP (2011) Theoretical evidence for the functional benefit of root cortical aerenchyma in soils with low phosphorus availability. Ann Botany 107:829-841

62. Qin R, Stamp P, Richner W (2005) Impact of tillage and banded starter fertilizer on maize root growth in the top 25 centimeters of the soil. Agron J 97:674-683

63. Rogers ED, Monaenkova D, Mijar M, Nori A, Goldman DI, Benfey PN (2016) X-ray computed tomography reveals the response of root system architecture to soil texture. Plant Physiol 171:20282040

64. Rosskopf U, Uteau D, Peth S (2021) Effects of mucilage concentration at different water contents on mechanical stability and elasticity in a loamy and a sandy soil. Eur J Soil Sci. doi:

10.1111/ejss. 13189

65. Rosskopf U, Uteau D, Peth S Development of mechanical soil stability in an initial homogeneous loamy and sandy soil under in situ field conditions. Plant and Soil: submitted PLSO-D-21-01865

66. Ruiz S, Koebernick N, Duncan S, Fletcher DM, Scotson C, Boghi A, Marin M, Bengough AG, George T, Brown $L$ (2020) Significance of root hairs at the field scale-modelling root water and phosphorus uptake under different field conditions. Plant Soil 447:281-304

67. Sarquis JI, Jordan WR, Morgan PW (1991) Ethylene evolution from maize (Zea mays L.) seedling roots and shoots in response to mechanical impedance. Plant Physiol 96:1171-1177

68. Schmidt S, Bengough AG, Gregory PJ, Grinev DV, Otten W (2012) Estimating root-soil contact from 3D X-ray microtomographs. Eur J Soil Sci 63:776-786

69. Segal E, Kushnir T, Mualem Y, Shani U (2008) Water uptake and hydraulics of the root hair rhizosphere. Vadose Zone J 7:1027-1034

70. Sene M, Vepraskas M, Naderman G, Denton H (1985) Relationships of soil texture and structure to corn yield response to subsoiling. Soil Sci Soc Am J 49:422-427

71. Strock CF, de la Morrow L, Lynch JP (2018) Reduction in root secondary growth as a strategy for phosphorus acquisition. Plant Physiol 176:691-703

72. Tang W, Lin W, Zhou X, Guo J, Dang X, Li B, Lin D, Yang Z (2021) Mechano-transduction via the pectin-FERONIA complex activates ROP6 GTPase signaling in Arabidopsis pavement cell morphogenesis. Curr Biol. doi: 10.1016/j.cub.2021.11.031

73. Vejchasarn P, Lynch JP, Brown KM (2016) Genetic variability in phosphorus responses of rice root phenotypes. Rice 9:1-16

74. Vetterlein D, Lippold E, Schreiter S, Phalempin M, Fahrenkampf T, Hochholdinger F, Marcon C, Tarkka M, Oburger E, Ahmed M, Javaux M, Schlüter S (2021) Experimental platforms for the investigation of 
spatiotemporal patterns in the rhizosphere - laboratory and field scale. J Plant Nutr Soil Sci 184:3550. doi: 10.1002/jpln.202000079

75. Vierheilig H, Coughlan AP, Wyss U, Piché $Y$ (1998) Ink and vinegar, a simple staining technique for arbuscular-mycorrhizal fungi. Appl Environ Microbiol 64:5004-5007

76. Warnaars B, Eavis B (1972) Soil physical conditions affecting seedling root growth. Plant Soil 36:623-634

77. Wen Z, Li H, Shen Q, Tang X, Xiong C, Li H, Pang J, Ryan MH, Lambers H, Shen J (2019) Tradeoffs among root morphology, exudation and mycorrhizal symbioses for phosphorus-acquisition strategies of 16 crop species. New Phytol 223:882-895

78. York LM, Carminati A, Mooney SJ, Ritz K, Bennett MJ (2016) The holistic rhizosphere: integrating zones, processes, and semantics in the soil influenced by roots. J Exp Bot 67:3629-3643

79. York LM, Nord E, Lynch J (2013) Integration of root phenes for soil resource acquisition. Front Plant Sci 4:355

\section{Figures}




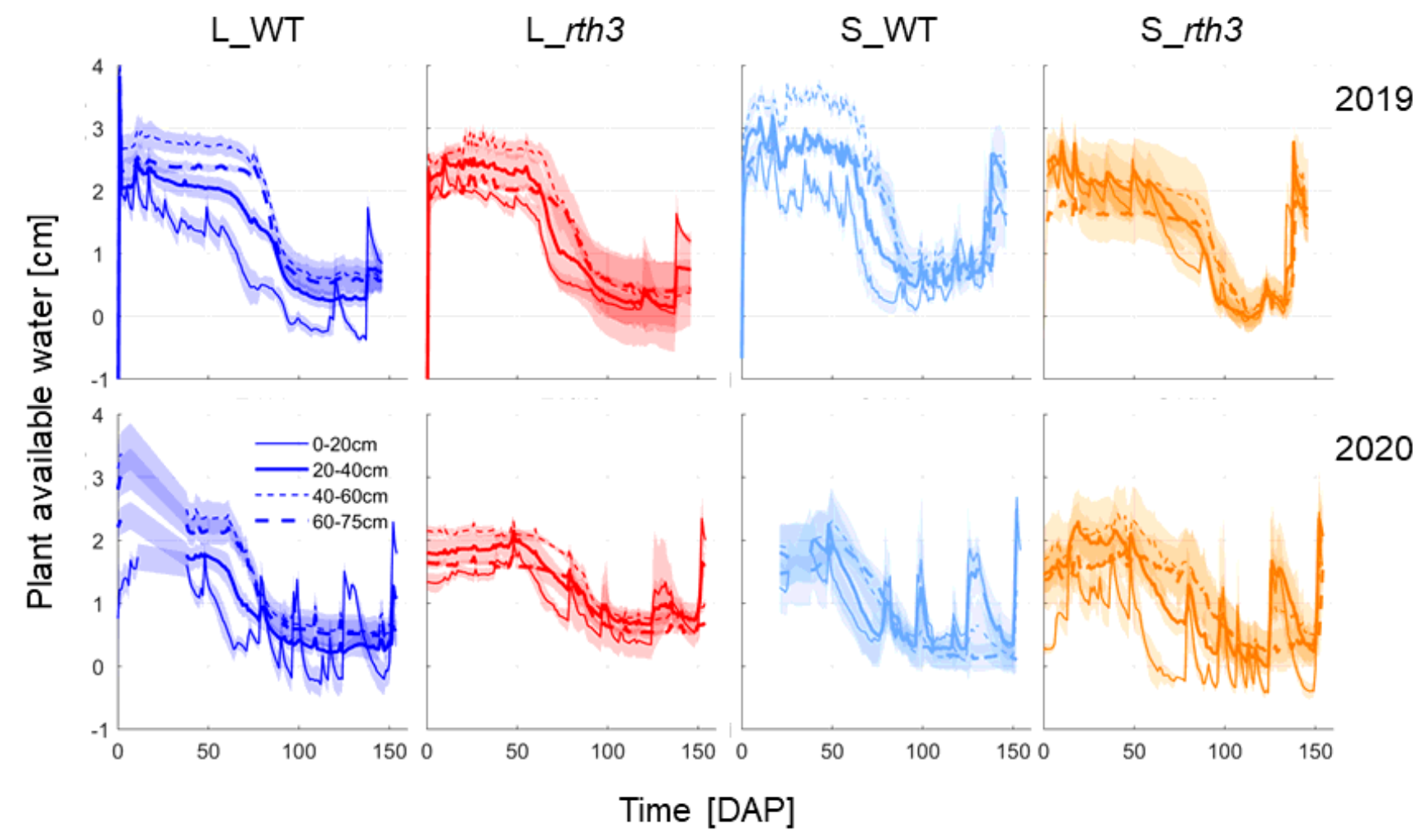

\section{Figure 1}

Time course of plant available water during the growing season in 2019 and 2020 for loam and sand planted with wild-type and root hair mutant, respectively. Data are based on measurement in the respective soil depths. Note that growth stage $B B C H 14$ corresponds to 42 days after planting (DAP), $\mathrm{BBCH} 19$ to DAP 63 ; BBCH 59 to DAP 98 and BBCH 83 to DAP154 in 2019. The semi-transparent band shows standard deviation, referring to $n=3$ sensors within the same depth in an individual plot.

\section{Figure 2}

Impact of substrate (loam, sand) and maize genotype (wild-type-WT, root hair mutant rth3-rth3) on plant nutrient status at different stages of plant development (BBCH 14, BBCH 19, $\mathrm{BBCH} 59$ ) in the first year of soil plot experiment (2019) indicated by N, P, K concentration in youngest unfolded leaves. Statistics: two-factorial ANOVA in conjunction with Tukey's HSD test was conducted for each growth stage. Significant effect of factor is denoted by $\mathrm{s}$ for substrate, $\mathrm{g}$ for genotype and $\mathrm{x}$ for interaction. 
Differences between treatments $(p<0.05)$ are indicated by different lower case letters. Whiskers indicate standard error, $n=6$. The grey shaded areas show the ranges for adequate supply according to (Bergmann 1986).

\section{Figure 3}

Impact of substrate (loam, sand) and maize genotype (wild-type-WT, root hair mutant rth3-rth3) on shoot dry weight at different stages of plant development (BBCH 14, $\mathrm{BBCH} 19, \mathrm{BBCH} 59, \mathrm{BBCH} 83$ ) in the first (2019) and second (2020) year of soil plot experiment. Note the different scales for the different growth stages. Statistics: two-factorial ANOVA in conjunction with Tukey's HSD test was conducted for each growth stage. Significant effect of factor is denoted by $s$ for substrate, $g$ for genotype and $\mathrm{x}$ for interaction. Differences between treatments $(p<0.05)$ are indicated by different lower case letters. Whiskers indicate standard error, $n=6$. Bold letters refer to 2019, italic letters to 2020 .

\section{Figure 4}

Impact of substrate (loam, sand) and maize genotype (wild-type-WT, root hair mutant rth3-rth3) on shoot $\mathrm{P}$ content and $\mathrm{P}$ uptake per unit root surface at different stages of plant development (BBCH 14, $\mathrm{BBCH} 19, \mathrm{BBCH} 59, \mathrm{BBCH} 83$ ) in the first year (2019) of soil plot experiment. Note the different scales for the different growth stages. Statistics: two-factorial ANOVA in conjunction with Tukey's HSD test was conducted for growth stage. Significant effect of factor is denoted by $s$ for substrate, $g$ for genotype and $x$ for interaction. Differences between treatments $(p<0.05)$ are indicated by different lower case letters. Whiskers indicate standard error, $n=6$.

\section{Figure 5}

Impact of substrate (loam, sand) and maize genotype (wild-type-WT, root hair mutant rth3-rth3) on root length density distribution with depth at different stages of plant development $(\mathrm{BBCH} 14, \mathrm{BBCH} 19, \mathrm{BBCH}$ $59, \mathrm{BBCH} 83$ ) in the first (2019) and second (2020) year of soil plot experiment. Note the different scales for the different growth stages; $n$.d. indicates that no values were determined. Statistics: two-factorial ANOVA in conjunction with Tukey's HSD test was conducted for growth stage, for each depth. Significant effect of factor across depth is denoted by $s$ for substrate, $g$ for genotype and $x$ for interaction. Differences between treatments $(p<0.05)$ are indicated by different lower case letters. Whiskers indicate standard error, $n=6$. Bold letters refer to 2019, italic letters to 2020 . 


\section{Figure 6}

Impact of substrate (loam, sand) and maize genotype (wild-type-WT, root hair mutant rth3-rth3) on mean root diameter in different depths, at different stages of plant development (BBCH 14, BBCH 19, BBCH 59, BBCH 83) in the first (2019) and second (2020) year of soil plot experiment. Statistics: twofactorial ANOVA in conjunction with Tukey's HSD test was conducted for growth stage, for each depth. Significant effect of factor is denoted by $\mathrm{s}$ for substrate, $\mathrm{g}$ for genotype and $\mathrm{x}$ for interaction. Differences between treatments for each depth $(p<0.05)$ are indicated by different lower case letters. Whiskers indicate standard error, $n=6$. Bold letters refer to 2019, italic letters to 2020 .

\section{Figure 7}

Impact of substrate (loam, sand) and maize genotype (wild-type-WT, root hair mutant rth3-rth3) on the ratio of cortex width to width of the vascular bundle (left) and the degree of aerenchyma formation (centre) in 20-40 cm depth at two growth stages (BBCH 19, BBCH 59) in the first (2019) and second (2020) year of soil plot experiment. Scale used for aerenchyma scoring is indicated on the right. Statistics: two-factorial ANOVA in conjunction with Tukey's HSD test was conducted for growth stage. Significant effect of factor is denoted by $s$ for substrate, $g$ for genotype and $x$ for interaction. Differences between treatments $(p<0.05)$ are indicated by different lower case letters. Whiskers indicate standard error, $n=6$. Bold letters refer to 2019, italic letters to 2020 .

\section{Figure 8}

Impact of substrate (loam, sand) and maize genotype (wild-type-WT, root hair mutant $r$ th $3-r$ th3) on the colonisation of roots by arbuscular mycorrhiza for different depths at different growth stages (BBCH 14, BBCH 19, BBCH 59) in the first year (2019) of soil plot experiment. Statistics: two-factorial ANOVA in conjunction with Tukey's HSD test was conducted for growth stage and depths. Significant effect of factor is denoted by $\mathrm{s}$ for substrate, $\mathrm{g}$ for genotype and $\mathrm{x}$ for interaction. Differences between treatments $(p<0.05)$ are indicated by different lower case letters; $n=6$.

\section{Figure 9}

Impact of substrate (loam, sand) and maize genotype (wild-type-WT, root hair mutant rth3-rth3) on root to shoot dry weight ratio at different stages of plant development $(\mathrm{BBCH} 14, \mathrm{BBCH} 19, \mathrm{BBCH} 59, \mathrm{BBCH}$ 83) in the first (2019) and second (2020) year of soil plot experiment. Statistics: two-factorial ANOVA in conjunction with Tukey's HSD test was conducted for growth stage. Significant effect of factor is denoted by $s$ for substrate, $g$ for genotype and $x$ for interaction. Differences between treatments $(p<0.05)$ are 
indicated by different lower case letters. Whiskers indicate standard error, $\mathrm{n}=6$. Bold letters refer to 2019, italic letters to 2020 .

\section{Figure 10}

Impact of substrate (loam, sand) and maize genotype (wild-type-WT, root hair mutant rth3-rth3) on water use efficiency at different stages of plant development (BBCH 14, BBCH 19, BBCH 59) in the first (2019) and second (2020) year of soil plot experiment. Note that soil water extraction data are based on field measurement summed up across the soil profile (Jorda et al. submitted) for one replicate of each treatment. For comparison inset provides data for the same treatments in the twin laboratory experiment (SCE) for growth stage BBCH 14 under well-watered conditions (Lippold et al. 2021). WUE is provided with (shoot plus root) and without (shoot) including root dry weight.
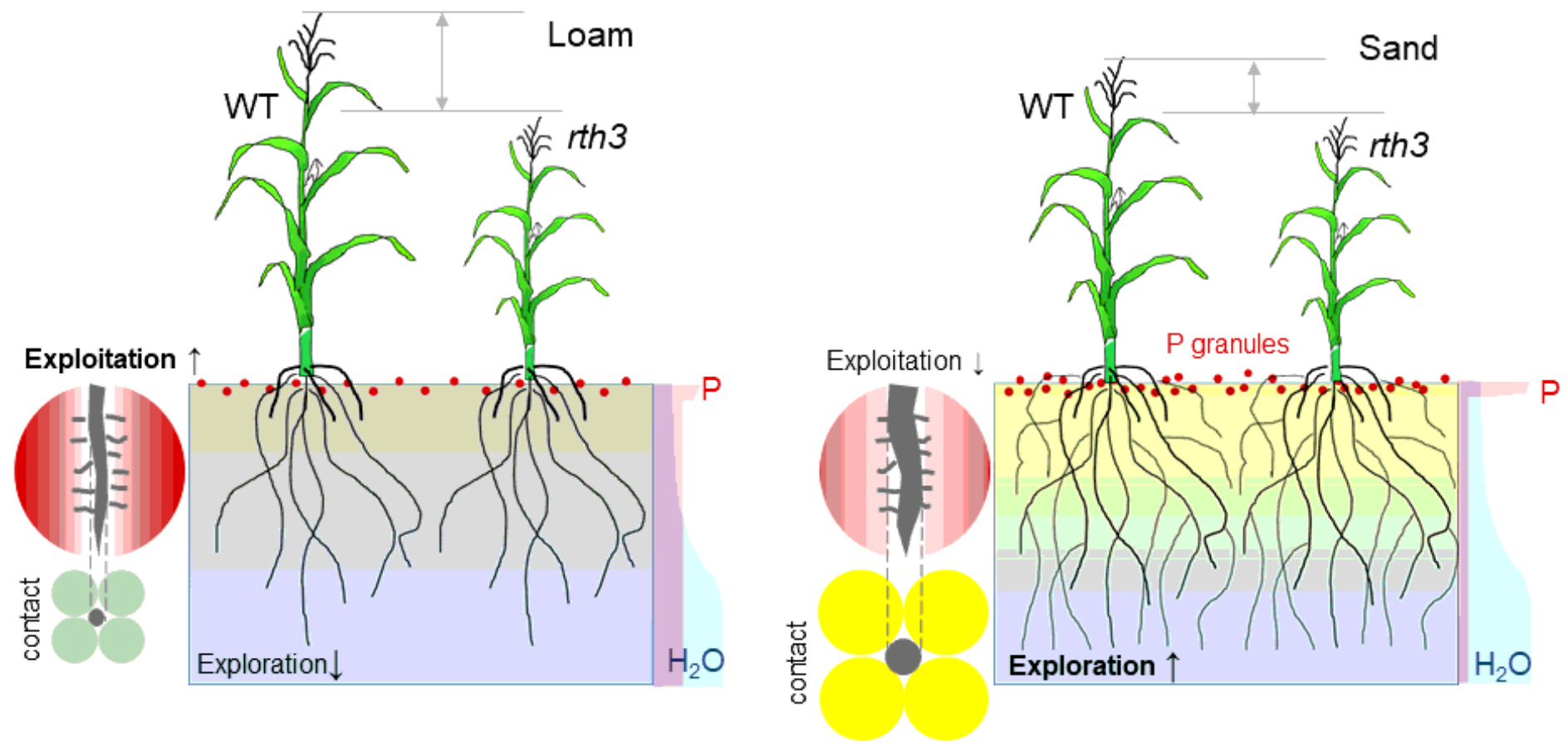

Figure 11 
Graphical summary with schematic representation of the response of shoot and root growth of maize wild type and root hair mutant $r$ th 3 to texture (loam and sand). The genotypes differed in shoot growth, with greater differences in loam than in sand. For root traits, especially root length density and root diameter, the differences between genotypes were small, but texture resulted in a large plasticity. The higher investment in root length density in sand is related to the lower concentration of plant-available nutrients in sand than in loam, which favours exploration over exploitation. Larger root diameters in sand than in loam are more likely explained by the need for soil contact of the roots.

\section{Supplementary Files}

This is a list of supplementary files associated with this preprint. Click to download.

- Supplement.docx

- Figs1.tif

- Figs2.tif

- FigS3.tif

- Figs4.tif

- Figs5.tif 